Discussion Paper No. 1054

\title{
IMMIGRATION AND SECULAR STAGNATION
}

\author{
Kaz Miyagiwa \\ Yoshiyasu Ono
}

May 2019

The Institute of Social and Economic Research Osaka University

6-1 Mihogaoka, Ibaraki, Osaka 567-0047, Japan 


\title{
Immigration and Secular Stagnation*
}

\author{
by \\ Kaz Miyagiwa** and Yoshiyasu Ono $^{\dagger}$
}

May 9, 2019

\begin{abstract}
We examine the effect of immigration on the host-country economy in the dynamic model that can deal with secular unemployment. Immigration has contrasting effects, depending on the economic state of the host country. If it suffers from unemployment, an influx of immigrants worsens unemployment and decreases consumption by natives. If instead the host country has full employment, immigration boosts native consumption while maintaining full employment, provided that immigrants are not too numerous. An influx of too many immigrants however can trigger stagnation. We also find that immigrants' remittances are harmful to natives under full employment but beneficial under secular stagnation.
\end{abstract}

JEL: F16, F22, F41

Keywords: Immigration, unemployment, secular stagnation, aggregate demand deficiency, remittances

*The authors thank seminar participants at ISER, Osaka University, and Wayne State University, for their valuable comments. Ono acknowledges financial support from the Joint Usage/Research Center at ISER, Osaka University, and the Grants-in-Aid for Scientific Research (\#15H05728), the Japan Society for the Promotion of Science (JSPS).

** Department of Economics, Florida International University, Miami, FL33199, U.S.A. E-mail: kmiyagiwa@gmail.com

${ }^{\dagger}$ Institute of Social and Economic Research, Osaka University, 6-1, Mihogaoka, Ibaraki, Osaka 567-0047, JAPAN. E-mail: ono@iser.osaka-u.ac.jp. 


\section{Introduction}

In recent years immigration has once again become a contentious issue in the United States and other developed economies. It is estimated that more than one million immigrants have entered the U.S. every year since $2000 .{ }^{1}$ The situation is not different in the E.U. In 2017, for example, 2.4 million immigrants entered the EU from non-EU countries. ${ }^{2}$ Canada, Australia, and New Zeeland have faced similar situations in recent years. Even Japan is no longer completely immune to illegal immigration.

Motivated by such resurgences of immigration, we present a new model of immigration from the perspectives of host countries. Although there already exists extensive literature investigating the impact of immigration, most of this, to be reviewed below, has focused on the "real side" of the economy, applying standard microeconomic tools. Departing from this tradition, this paper presents the dynamic model in which the real and the monetary side of the economy play key roles. The attractive feature of this model is that we can explain both full employment and unemployment from the agent's intertemporal welfare-maximizing behavior without introducing additional constraints.

In the next two sections we present the benchmark model of a small open country (ignoring immigration). This benchmark model is an extension of the closed-country models of Ono (1994, 2001), Ono and Ishida (2014) and Michau (2018) to an international setting, where the small host country is open to the world capital and equity markets. All agents are infinitely-lived and maximize intertemporal utility with respect to consumption of the aggregate good and real money balances, given the initial endowments of internationally traded assets.

\footnotetext{
${ }^{1}$ https://cis.org/Report/Record-445-Million-Immigrants-2017

${ }^{2}$ https://ec.europa.eu/eurostat/statistics.../Migration_and_migrant_population_statistics
} 
The model shares two salient features with Ono $(1994,2001)$. One is that marginal utility of real balances is bounded away from zero. The other is that, although the labor market adjusts according to the Walrasian mechanism, adjustment is not instantaneous. Of the two features, foremost in importance for our analysis is the boundedness of marginal utility of real balances, for sluggish wage adjustment cannot cause chronic unemployment in our model. As long as there is unemployment, the nominal wage and price keep falling, expanding real money balances. Therefore, if marginal utility of real balances can fall to zero, hoarding money eventually becomes worthless, prompting consumers to spend. A surge in spending boosts aggregate demand, creates jobs and stimulates more spending - a favorable process that continues until full employment is restored. However, if marginal utility of real balances is bounded away from zero, hoarding money never completely loses its luster. As a consequence, spending never picks up despite expanding real balances, stymieing the above process and condemning the economy to secular unemployment and stagnation.

The benchmark model yields the following results. The country enjoys full employment if it holds internationally traded equities below some threshold level, to be specified later. Otherwise, it suffers from unemployment.

We then turn to our main question: how an influx of immigrants can affect the host country. Immigrants are assumed to have the same preference system as host-country natives but differ in two respects. First, immigrants enter the host country with a given number of internationally traded assets but no host-country currency. Thus, immigrants exchange part of the international assets they hold for host-country currency to satisfy their demands for real balances. Second, immigrants remit part of their earnings to the families and relatives back home, whereas natives have no such obligations.

Our key findings can now be stated. (1) If natives are fully employed before immigration, then after immigration they not only remain fully employed but consume a greater quantity of 
the good. This favorable result of immigration however is predicated on immigrants being neither too many nor too rich (in the sense defined later). An influx of immigrants who are too many or too rich can turn the host country from full employment to stagnation. (2) By contrast, if there is unemployment initially, an influx of immigrants always reduces consumption and worsens unemployment. (3) Immigrants' remittances also have contrasting effects, depending on the state of the host-country economy. If there is full employment initially, remittances lower native consumption whereas if there is unemployment, remittances boost native consumption and employment.

We now review the relevant literature. There exists an extensive volume of literature, both formal and descriptive, investigating various aspects of immigration and immigration policies. To save space, we restrict our review to formal studies only. Early literature has treated immigration as a case of international factor mobility within standard factor-endowment trade models. ${ }^{3}$ Although this approach has yielded many valuable insights, subsequent research has come to emphasize the specific features of labor mobility as opposed to capital mobility. Pioneering in this line of research, Ethier (1985) has focused on the temporary migration motivated by guest-worker programs administered in West Germany and elsewhere at that time. However, it has turned out that most of temporary immigrants in Europe have opted to stay permanently. Also, most of todays’ immigrants appear to be permanent settlers rather than temporary job-seekers. In this paper, therefore, we study the effect of permanent immigration.

More recent work on immigration has turned attention to the presence of unemployment in host countries, investigating how immigrants and host-country immigration policies can affect the employment of native labor forces. ${ }^{4}$ This strand of research has typically adopted

\footnotetext{
${ }^{3}$ See e.g., Berry and Soligo (1969), Dixit and Norman (1980) and Markusen (1983).

${ }^{4}$ Ethier (1986) is the first to have highlighted host-country unemploymnet in his study of illegal immigration. Subsequent work on illegal immigration, with and without unemployment, includes Bonds and Chen (1987), Djajić (1997), Carter (1999), Woodland and Yoshida (2006), Liu (2010), Mangin and Zenou (2016), and
} 
search-theoretic approaches, where unemployment arises as an equilibrium phenomenon. ${ }^{5}$ For example, Liu (2010), Chassamboulli and Palivos (2014) and Battisti et al. (2018) have utilized such an approach to examine how an influx of immigrants affects natives' wages and welfare, while Ortega (2000), Miyagiwa and Sato (2019) have studied the effect of host country immigration policy under endogenous immigration flows. The present paper is a contribution to this line of research. Departing from these precursory studies, however, the present work is unique in that it deals with involuntary unemployment instead of frictional unemployment. ${ }^{6}$

The remainder of this paper is organized in 6 sections. The next section describes the general environment of the model. Section 3 presents the benchmark model of a small open economy and studies its properties in the absence of immigration. Section 4 details how the benchmark model is adapted so as to introduce immigration into our analysis. Section 5 studies the effect of immigration when the host country enjoys full employment prior to immigration. Section 6 extends the analysis to the case in which the host country suffers from stagnation. Section 7 concludes.

\section{Environment}

Consider a small open host country in a continuous infinite-time horizon. The country produces the aggregate product with labor and capital according to the neoclassical production function $F(L(t), K(t))$, where $K(t)$ and $L(t)$ are quantities of capital and labor used at time $t$. (The time index $t$ is suppressed unless ambiguities arise.) Since $F$ exhibits constant returns to scale and diminishing returns to each factor, we can rewrite it as

$$
F(L, K)=f(n) K
$$

\footnotetext{
Miyagiwa and Sato (2019), among others.

${ }^{5}$ Pissarides (2000) is the standard reference for equilibrium unemployment.

${ }^{6}$ See Ono (2010) for a formal analysis of Japan's economic slump since the 1990s.
} 
where

$$
n \equiv L / K
$$

The host country is open to the world capital market and takes the world equity rate $r$ as given. Capital moves freely across borders to instantaneously adjust the host country’s capital stock so as to keep the domestic real equity rate locked at $r$. We ignore investment, to keep things simple. Then firms carry no state variables. Firms competitively maximize momentary profits $f(n) K-w n-r K$ at each instant, taking $w$ (the real wage) and $r$ as given. This yields the first-order conditions:

$$
\begin{gathered}
f^{\prime}(n)=w, \\
f(n)-n f^{\prime}(n)=r,
\end{gathered}
$$

which uniquely determine $n$ and $w$, given $r$. Note that these values are independent of time.

All individuals are endowed with one unit of labor. They derive no utility from leisure, preferring to supply their entire labor endowments to the labor market. However, that is not always possible due to a demand shortage. In anticipation of such possibilities, let $\sigma$ denote the realized rate of employment, with range

$$
0 \leq \sigma \leq 1
$$

The typical individual's realized real labor income is given by $\sigma w$. When $\sigma=1$, we say there is full employment; otherwise, unemployment prevails.

All individuals $j$ have identical preferences, deriving momentary utility $u\left(c_{j}(t)\right)+$ $v\left(m_{j}(t)\right)$ from consuming $c_{j}(t)$ units of the aggregate good and holding real money balances $m_{j}(t)$ at time $t$. The subutility functions are assumed to satisfy 
Assumption 1: (a) For all $c_{j} \geq 0, u\left(c_{j}\right)$ is strictly increasing, strictly concave and twice continuously differentiable, and satisfies the Inada conditions; i.e., $\lim _{c_{j} \rightarrow+0} u^{\prime}\left(c_{j}\right)=\infty$ and $\lim _{c_{j} \rightarrow \infty} u^{\prime}\left(c_{j}\right)=0$

(b) For all $m_{j} \geq 0, v\left(m_{j}\right)$ is twice continuously differentiable with positive first derivatives and weakly concave. Specifically, there is $\bar{m}>0$ such that $v^{\prime}\left(m_{j}\right)$ is strictly decreasing for all $m_{j}<\bar{m}$ and $v^{\prime}\left(m_{j}\right)=\beta>0$ for all $m_{j} \geq \bar{m}$.

It is to be demonstrated, in the next section, that the presence of the lower bound $\beta>0$ on $v^{\prime}\left(m_{j}\right)$ is crucial for the existence of unemployment as discussed by Ono $(1994,2001)$ and Illing et al. (2018).

The representative individual maximizes the utility functional

$$
\int_{0}^{\infty}\left(u\left(c_{j}\right)+v\left(m_{j}\right)\right) \exp (-\rho t) d t
$$

where $\rho$ denotes the subjective discount rate, subject to the stock budget constraint and the flow budget equation:

$$
\begin{gathered}
a_{j}=m_{j}+b_{j}, \\
\dot{a}_{j}=w \sigma+\left(r a_{j}-R m_{j}\right)-c_{j}-\tau_{j} .
\end{gathered}
$$

The stock asset constaint in (4) shows that agent $j$ can hold his real assets $a_{j}$ in two forms: real money balances and real equities (or bonds). The latter are traded in the world markets and yield the real return $r$ per unit (henceforth they are simply referred to as "bonds" and denoted by $b_{j}$.) By contrast, real money balances, denoted by $m_{j}$, are neither internationally traded nor yield any interest. Thus, the agent holding $a_{j}$ receives the real interest income equal to $r a_{j}=$ $r b_{j}+(r-R) m_{j}=r b_{j}-\pi m_{j}$, where $\pi \equiv R-r$ is the rate of inflation (deflation if negative) and $R$ is the nominal interest rate. The flow asset constraint in (5) describes how real asset 
holdings change over time (the "dot” over the variable denotes its time derivative; e.g., $\dot{a}_{j} \equiv$ $\left.d a_{j} / d t\right)$. The first term on the right is the agent's labor income. The second term is the real interest income as shown above. These income terms increase the value of his assets, while the other two items in (5) - consumption $c_{j}$ and remittances $\tau_{j}(>0)$ - diminish it.

The Hamiltonian of the utility maximization problem is given by

$$
H=u\left(c_{j}\right)+v\left(m_{j}\right)+\lambda\left(w \sigma+r a_{j}-R m_{j}-c_{j}-\tau_{j}\right)
$$

where $\lambda$ is the co-state variable. The first-order conditions are

$$
\begin{gathered}
\lambda=u^{\prime}\left(c_{j}\right), \\
\lambda R=v^{\prime}\left(m_{j}\right), \\
\dot{\lambda}=(\rho-r) \lambda,
\end{gathered}
$$

which combine to yield the optimality condition that $c_{j}$ and $m_{j}$ must fulfill at each instant:

$$
\rho+\pi+\eta_{j} \frac{\dot{c}_{j}}{c_{j}}=R=\frac{v^{\prime}\left(m_{j}\right)}{u^{\prime}\left(c_{j}\right)}
$$

where $\eta_{j} \equiv-u^{\prime \prime} c_{j} / u^{\prime}>0$. Condition (6) has the intuitive explanation. The left-hand side represents the intertemporal marginal rate of substitution in consumption measured in nominal terms, or what we refer to as the desire to consume (now instead of later). If the left-hand side is less than the nominal interest rate $R$, the individual would decrease consumption. The right-hand side of (6) measures the intratemporal rate of substitution between real balances and consumption. This is also called the desire to hold real balances or more simply the "liquidity premium.” If the right-hand side is greater than $R$, the individual would sell bonds to increase real balances. Thus, if (6) holds, no one has the incentive to change his consumption level and real money balances. In addition to (6), the optimal $c_{j}$ and $a_{j}$ must fulfill the transversality condition:

$$
\lim _{t \rightarrow \infty} u^{\prime}\left(c_{j}(t)\right) a_{j}(t) \exp (-\rho t)=0
$$


Turning to the money market, we assume to keep things simple that the host-country monetary authority keeps the country’s money supply fixed at $M^{S}$ (We relax this assumption slightly when discussing the effect of immigration in section 4.) The equilibrium in the money market requires

$$
\frac{M^{S}}{P}=m,
$$

where $m$ denotes the economy-wide real balances and $P$ is the nominal price. Time differentiation of (8) yields

$$
\dot{m}=-\pi m \text {. }
$$

The small host country takes the international nominal price $P^{I}$ of the aggregate product as given. Since the product is traded freely in the international market, the exchange rate $\epsilon$ adjusts instantaneously to satisfy

$$
P=\epsilon P^{I} \text {. }
$$

As is customary in all standard small-open economy models, we assume

Assumption 2: $\rho=r$.

We henceforth use $\rho$ and $r$ interchangeably. Setting $\rho=r(=R-\pi)$ in (6) yields

$$
\frac{\dot{c}_{j}}{c_{j}}=0
$$

Assumption 2 thus implies that $c_{j}(j=i, h)$ is constant over time. This fact enables us to rewrite (6) as

$$
\rho+\pi=R=\frac{v^{\prime}\left(m_{j}\right)}{u^{\prime}\left(c_{j}\right)} \text { for } j=i, h \text {. }
$$

Finally, we adopt the conventional Walrasian wage adjustment mechanism in the labor market. More specifically, when there is unemployment, the nominal wage $W$ declines over time according to 


$$
\frac{\dot{W}}{W}=\alpha(\sigma-1)
$$

where the constant $\alpha(>0)$ represents the speed of adjustment. ${ }^{7}$ In contrast, when there is full employment upward wage adjustment is assumed to occur instantaneously. Full employment or not, equations (1) and (2), together with assumption 2, imply that $P$ and $W$ move in tandem to keep the real wage constant $(w=W / P)$. Given that the money supply $M^{s}$ does not expand over time, we can summarize the above price adjustment process as follows: ${ }^{8}$

$$
\begin{gathered}
\pi=\alpha(\sigma-1)<0 \text { for } \sigma<1, \\
\pi=0 \text { for } \sigma=1
\end{gathered}
$$

\section{The model without immigration (benchmark)}

In this section we present the benchmark model, i.e., the model without immigration, where we let $j=h$ (standing for "host-country natives"). To keep the analysis simple, we normalize the native population size to one. With this normalization, the budget constraints (4) and (5) apply to the whole country, with $m=m_{h}$. Substituting from (4) and applying (9) enables us to rewrite the flow budget constraint (5) as

$$
\dot{b}_{h}=\rho b_{h}+w \sigma-c_{h} .
$$

We prove, in the appendix, that the host-country economy is always in a steady state and that its current account is always balanced accordingly. Therefore, if $b_{h}^{0}$ denotes the native's initial bond holdings, taken as exogenous, we have $b_{h}=b_{h}^{0}$. Substituting this in (13) and letting $\dot{b}_{h}=0$ yields

$$
c_{h}=w \sigma+\rho b_{h}^{0}
$$

\footnotetext{
${ }^{7}$ Ono and Ishida (2014) present the microfoundations of wage adjustment mechanism that converges to such adjustment.

${ }^{8}$ Schmitt-Grohé and Uribe (2016, 2017) also assume a similar wage adjustment mechanism.
} 
The right-hand side represents the native's total income, comprising the wage income and the interest income from his bond holdings. (14) shows that the native consumes all his income.

\subsection{The benchmark model with full employment}

If the host country has full employment, the benchmark model can be solved recursively. First, we have $\sigma=1$. Setting it in (14) pins down the consumption level:

$$
c_{h}=c_{h}^{F} \equiv w+\rho b_{h}^{0}{ }^{9}
$$

Under full employment the nominal wage and price are constant $(\pi=0)$ from $(12)$, so we can rewrite (11) as

$$
\rho=\frac{v^{\prime}\left(m_{h}^{F}\right)}{u^{\prime}\left(c_{h}^{F}\right)}
$$

Substituting the above $c_{h}^{F}\left(\equiv w+\rho b_{h}^{0}\right)$ into (15) determines the native's real balances $m_{h}^{F}$. Since $m_{h}^{F}=m$ under the normalization of the native population to unity, the money market-clearing condition (8) determines the nominal price $P$, given the money supply $M^{s}$. The exchange rate then adjusts to satisfy (10).

Having solved the benchmark model, we ask under what conditions the host country has full employment. To that end, let $\bar{c}$ be given by

$$
\rho=\frac{\beta}{u^{\prime}(\bar{c})}
$$

Combining (15) and (16) yields

$$
\rho=\frac{v^{\prime}\left(m_{h}\right)}{u^{\prime}\left(c_{h}^{F}\right)}=\frac{\beta}{u^{\prime}(\bar{c})}
$$

Since $v^{\prime}\left(m_{h}\right) \geq \beta$ by assumption 1 (b), the above equation implies that

$$
c_{h}^{F} \equiv w+\rho b_{h}^{0} \leq \bar{c} .
$$

\footnotetext{
${ }^{9}$ We assume $b_{h}^{0}>-w / \rho$ to ensure $c_{h}^{F}>0$.
} 
That is, consumption is bounded from above by $\bar{c}$. In the next subsection we show that the converse of this result holds. Thus, condition (17) is both necessary and sufficient for the existence of an equilibrium with full employment. Moreover, this equilibrium is unique.

Proposition 1: Under assumptions 1 and 2 the model admits a unique equilibrium with full employment if and only if $c_{h}^{F}\left(\equiv w+\rho b_{h}^{0}\right) \leq \bar{c}$.

Recall that the native spends all his income on consumption. Therefore, if the native is endowed with a large sum of bonds, it is possible that his total income $\left(w+\rho b_{h}^{0}\right)$ exceeds the limit $\bar{c}$, violating condition (17). In such cases, there is no equilibrium with full employment by proposition 1 . We thus turn to the possibility of an equilibrium with unemployment.

\subsection{The benchmark model with unemployment}

We first characterize an equilibrium with unemployment. With unemployment, we have $\sigma<1$ and $\pi=\alpha(\sigma-1)<0$ by (12). Further, as the nominal price $P$ continues falling, the real balances $m=M^{s} / P$ keep expanding beyond the threshold level $\bar{m}$ so that $v^{\prime}\left(m_{h}\right)=\beta$ holds, enabling us to rewrite the optimality condition (11) as

$$
\rho+\alpha(\sigma-1)=\frac{\beta}{u^{\prime}\left(c_{h}\right)} .
$$

To ensure that the left-hand side of (18) remains positive, we assume

$$
\rho>\alpha
$$

that is, the speed of wage adjustment is not too fast.

Since the current account (13) must always be balanced, equation (14) holds despite deflation. Solving (14) and (18) simultaneously, we can determine the equilibrium consumption level and employment rate. We represent them in figure 1 . The 
monotone-increasing curve illustrates equation (18) while the straight line depicts equation (14). ${ }^{10}$ The intersection point A gives us the equilibrium values, denoted by $c_{h}^{*}$ and $\sigma^{*}$.

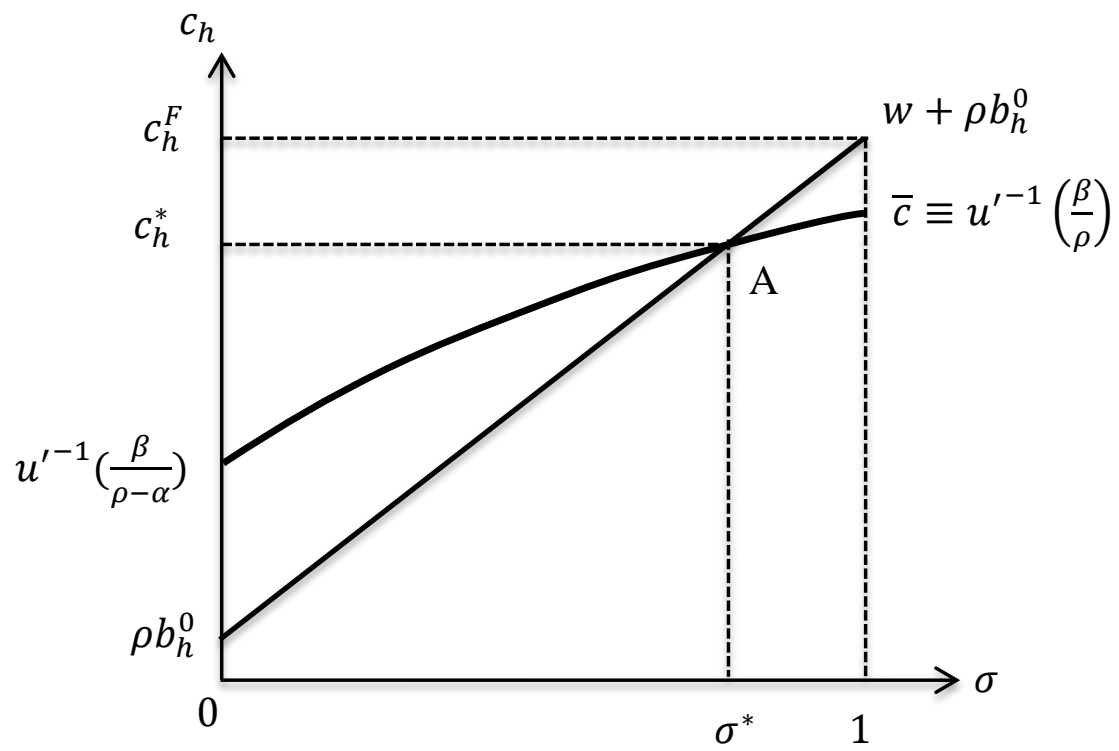

Figure 1:

Equilibrium with unemployment (benchmark)

We next investigate the condition giving rise to unemployment. Figure 1 indicates that there is unemployment $\left(0<\sigma^{*}<1\right)$ if the straight line is strictly above the curve at $\sigma=1$ and strictly below it at $\sigma=0 .{ }^{11}$ The first condition is satisfied if

$$
c_{h}^{F} \equiv w+\rho b_{h}^{0}>\bar{c}=u^{\prime-1}(\beta / \rho),
$$

while the second implies

$$
\rho b_{h}^{0}<u^{\prime-1}(\beta /(\rho-\alpha))
$$

Inverting condition (19) gives us $\rho<\beta / u^{\prime}\left(c_{h}^{F}\right)$. This inequality says that, under full employment, the desire to consume, $\rho$, is less than the desire to hold real balances, $\beta / u^{\prime}\left(c_{h}^{F}\right)$.

\footnotetext{
10 The graph of (18) is strictly upward-sloping but not necessarily concave as drawn in figure 1 .

${ }^{11}$ Figure 1 depicts the case in which $b_{h}^{0}>0$. That is just for the sake of presentation. If $b_{h}^{0}<0$, the straight line cuts the $\sigma$-axis at $\sigma>0$. This however does not affect our analysis, given that condition (20) holds.
} 
Thus, there cannot be full employment when (19) holds. ${ }^{12}$ On the other hand, condition (20) is more technical and rules out the possibility of zero employment.

The above discussion suggests that both conditions (19) and (20) are necessary for the existence of an equilibrium with unemployment. They are also sufficient because, if they both hold, an appeal to the intermediate-value theorem proves the existence of an equilibrium with $0<\sigma<1$

Moreover, if the equilibrium in figure 1 is unique, the straight line must be steeper than the curve at the intersection point. A little algebra shows that we can express this condition as

$$
\Omega \equiv w+\left(\frac{\alpha}{\beta}\right) \frac{\left(u^{\prime}\right)^{2}}{u^{\prime \prime}}>0 .
$$

For the remainder of our analysis we assume the equilibrium to be unique so condition (21) holds in its neighborhood.

Finally, we show that the transversality condition (7) is satisfied even though real balances $m_{h}$ keep expanding. Since the price falls at the rate $\pi(=\alpha(\sigma-1))$, we can write $m_{h}(t)=$ $m_{h}(0) \exp (-\pi t)$. Furthermore, from (18) we have

$$
\pi=\alpha(\sigma-1)=\frac{\beta}{u^{\prime}\left(c_{h}\right)}-\rho(<0) .
$$

We can substitute these into the first expression below to show that

$$
\lim _{t \rightarrow \infty} u^{\prime}\left(c_{h}\right) m_{h}(t) \exp (-\rho t)=\lim _{t \rightarrow \infty} u^{\prime}\left(c_{h}\right) m_{h}(0) \exp \left(-\frac{\beta}{u^{\prime}\left(c_{h}\right)} t\right)=0 .
$$

Because $b_{h}$ stays constant and equals $b_{h}^{0}$, the preceding result implies that

$$
\lim _{t \rightarrow \infty} u^{\prime}\left(c_{h}\right) a_{h}(t) \exp (-\rho t)=\lim _{t \rightarrow \infty} u^{\prime}\left(c_{h}\right)\left(m_{h}(t)+b_{h}^{0}\right) \exp (-\rho t)=0,
$$

proving that the transversality condition is satisfied.

The next proposition summarizes our findings of this subsection so far.

\footnotetext{
${ }^{12}$ This proves that (17) is also sufficient for the existence of an equilibrium with full employment, as alluded to in the paragraph leading to proposition 1 .
} 
Proposition 2: Under assumptions 1 and 2, there is an equilibrium with unemployment if and only if $b_{h}^{0}$ satisfies conditions (19) and (20). If it is unique, condition (21) holds in its neighborhood.

To understand what causes unemployment, suppose that $v^{\prime}\left(m_{h}\right)$ approaches zero instead of $\beta>0$ as $m_{h} \rightarrow \infty$. Then, the optimality condition (18) is replaced by

$$
\rho+\alpha(\sigma-1)=\frac{v^{\prime}\left(m_{h}\right)}{u^{\prime}\left(c_{h}\right)}
$$

As real balances keep expanding and driving $v^{\prime}\left(m_{h}\right)$ down toward zero, $c_{h}$ must keep increasing to satisfy condition (22). This continuous rise in consumption creates jobs, raising the employment rate $\sigma$ until full employment is achieved. Therefore, unemployment eventually disappears without the boundedness of marginal utility of real balances away from zero.

We now offer an intuitive explanation of Proposition 2. Suppose that the native's income $w+\rho b_{h}^{0}$ happens to equal $\bar{c}$. Then, the line and the curve in figure 1 meet only at $\sigma=1$, with the native consuming $\bar{c}=w+\rho b_{h}^{0} \equiv c_{h}^{F}$ and holding real balances $\bar{m}$. There is full employment supported by the optimality condition:

$$
\rho=\frac{v^{\prime}(\bar{m})}{u^{\prime}\left(c_{h}^{F}\right)}=\frac{\beta}{u^{\prime}(\bar{c})}
$$

If the native has more income $\left(w+\rho b_{h}^{0}>\bar{c}\right)$, there cannot be full employment. To show this, recall that consumption cannot exceed the limit $\bar{c}$; cf. (17). Conditions (18) and (19) imply that the consumption level cannot equal $\bar{c}$, either. If the native does consume $\bar{c}$, he has unspent income equaling $w+\rho b_{h}^{0}-\bar{c}>0$. If he and all other natives buy foreign assets with this excess income, the host country runs a perpetual current account surplus. Therefore, the host-country currency appreciates. Currency appreciation however makes host-country firms less competitive compared with foreign firms, prompting a cutback on employment and 
reducing the native's income to $w \sigma+\rho b_{h}^{0}$. The current account imbalance disappers completely only if the employment rate $(\sigma)$ falls enough to equate the native's income to his new consumption level; i.e., $w \sigma+\rho b_{h}^{0}=c_{h}$. This new consumption $c_{h}\left(=w \sigma+\rho b_{h}^{0}\right)$ must be less than $\bar{c}$ by (16) and (18) because $\sigma<1$.

The above discussion implies that $\rho b_{h}^{0}=\bar{c}-w$ is the native's maximum endowment of bonds consistent with full employment. If he holds fewer bonds than that, there is full employment by proposition 1 . If he holds more bonds, there is unemployment by proposition 2 . We record this result in

Corollary 1: (a) If $\rho b_{h}^{0} \leq \bar{c}-w$, the host country has full employment.

(b) If $\rho b_{h}^{0}>\bar{c}-w$, the host country suffers from unemployment.

\section{Immigration: an overview}

We now extend the benchmark model to study the effect of immigration on the host country. To that end, we assume the following. At some time, say $t=0$, a given number, say, $x_{i}$ of immigrants enter the host country (the subscript $i$ denotes immigrants). Like natives, immigrants are endowed with one unit of labor and maximize the utility functional given in (3). As mentioned in the introduction, however, immigrants differ in two respects. First, the typical immigrant arrives with $b_{i}^{0}$ units of internationally-traded bonds but with no host-country currency. Thus, upon entry, the immigrant sells bonds (or borrow against their future incomes) in exchange for local money to satisfy his demand for real balances. If each immigrant acquires $m_{i}$ units of the host-country currency from the monetary authority, the latter holds international bonds totaling $x_{i} m_{i}$. We assume that the monetary authority rebates the interest 
earnings from these bond holdings evenly to all natives. ${ }^{13}$ At the end of the day, it is as if each native has increased his bond holdings to $b_{h}^{0}+x_{i} m_{i}$ (each immigrant's bond holdings has fallen to $\left.b_{i}^{0}-m_{i}\right)$.

The second way immigrants differ from natives is with respect to remittances. It is assumed that each immigrant remits $\tau_{i}(\geq 0)$ units of the aggregate good back home whereas natives make no such remittances $\left(\tau_{h}=0\right)$. We take $\tau_{i}$ as given and investigate its effect.

With the above changes, we can write the native's flow asset constraint at $t>0$ as

$$
\dot{a}_{h}=\rho\left(b_{h}^{0}+x_{i} m_{i}\right)-\pi m_{h}+w \sigma-c_{h},
$$

and the immigrant's as

$$
\dot{a}_{i}=\rho\left(b_{i}^{0}-m_{i}\right)-\pi m_{i}+w \sigma-c_{i}-\tau_{i}
$$

Adding up these equations over all the host-country residents (i.e., natives and immigrants combined) gives us the aggregate flow budget constraint:

$$
\dot{a}(=\dot{b}+\dot{m})=\rho\left(b_{h}^{0}+x_{i} b_{i}^{0}\right)-\pi m+w \sigma\left(1+x_{i}\right)-\left(c_{h}+x_{i} c_{i}\right)-x_{i} \tau_{i},
$$

where we write $m \equiv m_{h}+x_{i} m_{i}$ (the variables without subscripts henceforth denote the aggregated values). Substituting from (9) and rearranging terms, we can rewrite the above constraint as

$$
\dot{b}=\rho\left(b_{h}^{0}+x_{i} b_{i}^{0}\right)+w \sigma\left(1+x_{i}\right)-\left(c_{h}+x_{i} c_{i}\right)-x_{i} \tau_{i}(=0) .
$$

As shown in the appendix, the right-hand side of (25) equals zero because the host country's current account must always be balanced $(\dot{b}=0)$.

\section{Full employment}

${ }^{13}$ If natives' income increases and conusmption is stimulated, they also try to expand money holdings by exchanging bonds for money. In order to cope with this request, the monetary authority has to supply money for bonds and the money stock instantaneously increases. The interest earnings on the newly acquired bonds are assumed to be distributed among natives. Such adjustment is instantaneously completed when accepting immigration. 
Suppose that we have full employment in a post-immigration equilibrium. With full employment $\sigma=1$, implying the constancy of the nominal wage and price over time ( $\pi=0$ ) by (12). The optimal consumption and real balances satisfy

$$
\rho=\frac{v^{\prime}\left(m_{h}\right)}{u^{\prime}\left(c_{h}\right)}=\frac{v^{\prime}\left(m_{i}\right)}{u^{\prime}\left(c_{i}\right)}\left(=\frac{\beta}{u^{\prime}(\bar{c})}\right)
$$

where the last equality follows from the definition of $\bar{c}$, cf. (16). Since $v^{\prime}\left(m_{j}\right) \geq \beta$, (26) implies that $c_{j} \leq \bar{c}$. As in the benchmark model, the consumption levels are bounded from above by $\bar{c}$. With the nominal price constant, the individual asset holdings do not change over time, either. This fact enables us to set $\dot{a}_{j}=0$ in the flow budget constraints (23) and (24). After some arrangement, we obtain

$$
\begin{gathered}
c_{h}=\rho\left(b_{h}^{0}+x_{i} m_{i}\right)+w, \\
c_{i}=\rho\left(b_{i}^{0}-m_{i}\right)+w-\tau_{i} .
\end{gathered}
$$

Equations (26), (27) and (28) determine the equilibrium levels of $c_{j}$ and $m_{j}$ for $j=h, i$, which will be called $\tilde{c}_{j}$ and $\tilde{m}_{j}$, respectively.

(26) is consistent with two types of equilibria to consider. In the first equilibrium, the immigrants hold $\widetilde{m}_{i} \leq \bar{m}$ while in the second the immigrant is rich enough to demand $\widetilde{m}_{i}>$ $\bar{m}$. We begin in the first case. With $\widetilde{m}_{i} \leq \bar{m}$, we can arrange (26) to obtain

$$
\tilde{m}_{i}=v^{\prime-1}\left(\rho u^{\prime}\left(\tilde{c}_{i}\right)\right) \equiv \varphi\left(\tilde{c}_{i}\right) \text { for } \tilde{m}_{i} \leq \bar{m} ; \quad \varphi^{\prime}(\cdot)>0, \quad \varphi(\bar{c})=\bar{m}
$$

Substituting for $\tilde{m}_{i}$ from (29) into (28) yields

$$
\tilde{c}_{i}+\rho \varphi\left(\tilde{c}_{i}\right)=\left(\rho b_{i}^{0}-\tau_{i}\right)+w .
$$

Given the monotonicity of $\varphi\left(c_{i}\right)$, (30) gives us a unique $\tilde{c}_{i}$. (30) implies that $\tilde{c}_{i}$ depends on his labor income $w$, interest income $\rho b_{i}^{0}$ and remittances $\tau_{i}$. The last two represent, in flow terms, his asset earnings less his financial obligations to his folks back home. Let us call the term $\left(\rho b_{i}^{0}-\tau_{i}\right)$ the immigrant's "net worth." We can substitute this $\tilde{c}_{i}$ into (29) to determine the real balances $\tilde{m}_{i}=\varphi\left(\tilde{c}_{i}\right)$. Since $\varphi^{\prime}>0$, as shown in (29), (30) implies 


$$
\rho b_{i}^{0}-\tau_{i} \uparrow \Rightarrow \tilde{c}_{i} \uparrow, \quad \tilde{m}_{i} \uparrow \text { for } \tilde{m}_{i} \leq \bar{m} .
$$

The immigrant having a greater net worth consumes more and demands more real balances. It is straightforward to show that there is a unique net worth given by

$$
\rho b_{i}^{0}-\tau_{i}=(\bar{c}-w)+\rho \bar{m}\left(\equiv N W^{0}\right),
$$

such that the immigrants consume $\tilde{c}_{i}=\bar{c}$ and hold $\tilde{m}_{i}=\bar{m}$. Then, (31) holds for all $\rho b_{i}^{0}-$ $\tau_{i}<N W^{0}$

If the immigrant is so rich that his net worth exceeds $N W^{0}$, then we have a second equilibrium, in which the immigrant consumes exactly $\bar{c}$ while holding $\widetilde{m}_{i}>\bar{m}$. Since marginal utility of real balances is bounded from below by $\beta$, consuming in excess of $\bar{c}$ puts the desire to hold real balances above the desire to consume. To fulfill the optimality condition (26), the immigrant must exchange more bonds for money, which reduces his interest income. In the end his income is brought down to equal $\bar{c}$ such that we have

$$
\bar{c}=\rho\left(b_{i}^{0}-m_{i}\right)+w-\tau_{i} .
$$

This last equation determines the immigrant's money balances:

$$
\tilde{m}_{i}=\rho b_{i}^{0}-\tau_{i}+w-\bar{c}>\bar{m}
$$

It is evident from the last two equations that

$$
\rho b_{i}^{0}-\tau_{i} \uparrow \Rightarrow \tilde{c}_{i}=\bar{c}, \quad \tilde{m}_{i} \uparrow \quad \text { for } \tilde{m}_{i}>\bar{m}
$$

(31) and (33) indicate that an increase in the immigrant's net worth always raises his real balances $\widetilde{m}_{i}$, whether $\widetilde{m}_{i}$ exceeds $\bar{m}$ or not.

In section 3 we showed that, when natives are rich enough to hold real balances above $\bar{m}$, there is no equilibrium with full employment (proposition 2). In the light of that result, the reader may be puzzled by the result that full employment prevails with immigrants holding $\tilde{m}_{i}>\bar{m}$. To understand why, notice that immigrants are fundamentally different from natives in the following sense. As explained above, no matter how rich they are, immigrants can sell as many bonds as needed to bring their income down to equal $\bar{c}$. By contrast, natives have no 
such latitude because, even if they sell bonds to reduce their income, the monetary authority gives the interest income on the acquired bonds back to natives, so natives cannot change their total income by selling bonds. As detailed in section 3, natives' income is reduced only by a fall in the employment rate.

The discussion so far enables us to specify the condition leading to an equilibrium with full employment in a post-immigration state. Since $\tilde{c}_{h} \leq \bar{c}$, (27) gives us the following result:

Proposition 3: There exists an equilibrium with full employment after immigration only if

$$
\rho b_{h}^{0}+w \leq \bar{c}-\rho x_{i} \widetilde{m}_{i},
$$

where $\widetilde{m}_{i}$ is determined by (29) and (30) or by (32).

If there is full employment before $t=0$, we have $\rho b_{h}^{0}+w \leq \bar{c}$ by (17). (34) implies (17); full employment in a post-immigration economy implies full employment prior to immigration.

We now complete the analysis by calculating for the equilibrium consumption and real money balances for natives. They follow readily by plugging the $\widetilde{m}_{i}$ given above into (26) and (27):

$$
\begin{aligned}
& \tilde{m}_{h}=v^{\prime-1}\left(\rho u^{\prime}\left(\tilde{c}_{h}\right)\right) \equiv \varphi\left(\tilde{c}_{h}\right), \\
& \tilde{c}_{h}=\rho\left(b_{h}^{0}+x_{i} \tilde{m}_{i}\right)+w(\leq \bar{c}) .
\end{aligned}
$$

The second of these equations says that $\tilde{c}_{h}$ increases with immigrants' real balances $\tilde{m}_{i}$. This is evident because natives' interest income increases as immigrants exchange more bonds for money. Moreover, as we saw in (31) and (33), the immigrant with a greater net worth $\left(\rho b_{i}^{0}-\tau_{i}\right)$ holds more money. These facts establish the next proposition.

Proposition 4: Suppose that (34) holds so that there is full employment before and after an influx of immigrants. Then: 
(1) Immigration increases natives’ consumption.

(2) The richer are immigrants (the more bonds they hold before immigration), the greater is natives' consumption.

(3) The greater remittances immigrants send home, the smaller is natives’ consumption.

Proposition 4 has the intuitive explanation. Immigrants bring international bonds with them and exchange some for host-country currency. While the host-country currency is useless in international transactions, the acquisition of internationally traded bonds allows natives to import and consume more. Since richer immigrants convert more international bonds into local currency, natives can consume greater quantities, provided that condition (34) holds.

Although (34) implies (17), the converse does not hold. If the native is so rich that his pre-immigration income is sufficiently close to the consumption limit $\bar{c}$, then his post-immigration income may exceed this consumption limit, due to the additional interest income $\rho x_{i} \widetilde{m}_{i}$ that the native receives after immigration, and (34) is violated. Similarly, an influx of too many or too rich immigrants or both can make the product $\rho x_{i} \widetilde{m}_{i}$ so large that (34) can be violated. In such cases, we can only have unemployment after immigration, the topic to which we turn in the next section.

\section{Unemployment}

We begin this section by characterizing a post-immigration equilibrium with unemployment. With unemployment $(\sigma<1)$, the nominal wage and price keep falling according to (12) so that $\pi<0$. The implication is that natives' real balances exceed the threshold $\bar{m}$, implying the optimality conditions:

$$
\rho+\alpha(\sigma-1)=\frac{\beta}{u^{\prime}\left(c_{h}\right)}=\frac{v^{\prime}\left(m_{i}\right)}{u^{\prime}\left(c_{i}\right)}\left(<\frac{\beta}{u^{\prime}(\bar{c})}\right) .
$$


The inequality, due to (16), implies that $c_{j} \leq \bar{c}$ for $j=h, i$. Given the fact that the price is continuously falling, (35) suggests two possible scenarios, depending on the size of the immigrant's real money balances $m_{i}$. One scenario has $m_{i}<\bar{m}$, while in the other $m_{i}$ keep increasing beyond $\bar{m}$.

Consider the case in which $m_{i}<\bar{m}$. Then, $m_{i}$ stays constant, implying that the immigrant's asset holding is not expanding despite deflation. This allows us to set $\dot{a}_{i}=0$ in (24) to obtain

$$
\rho b_{i}^{0}-\tau_{i}+\sigma w-c_{i}-[\rho+\alpha(\sigma-1)] m_{i}=0 .
$$

Equations (35) and (36) determine the immigrant's optimal real balances and consumption in terms of $\sigma$ and his net worth $\rho b_{i}^{0}-\tau_{i}$. Algebra establishes

$$
\begin{gathered}
m_{i}=m_{i}\left(\sigma ; \rho b_{i}^{0}-\tau_{i}\right), \frac{\partial m_{i}}{\partial\left(\rho b_{i}^{0}-\tau_{i}\right)}>0 \text { for } m_{i}<\bar{m} \\
c_{i}=c_{i}\left(\sigma ; \rho b_{i}^{0}-\tau_{i}\right), \frac{\partial c_{i}}{\partial\left(\rho b_{i}^{0}-\tau_{i}\right)}>0 \quad \text { for } c_{i}<u^{\prime-1}\left(\frac{\beta}{\rho+\alpha(\sigma-1)}\right) .
\end{gathered}
$$

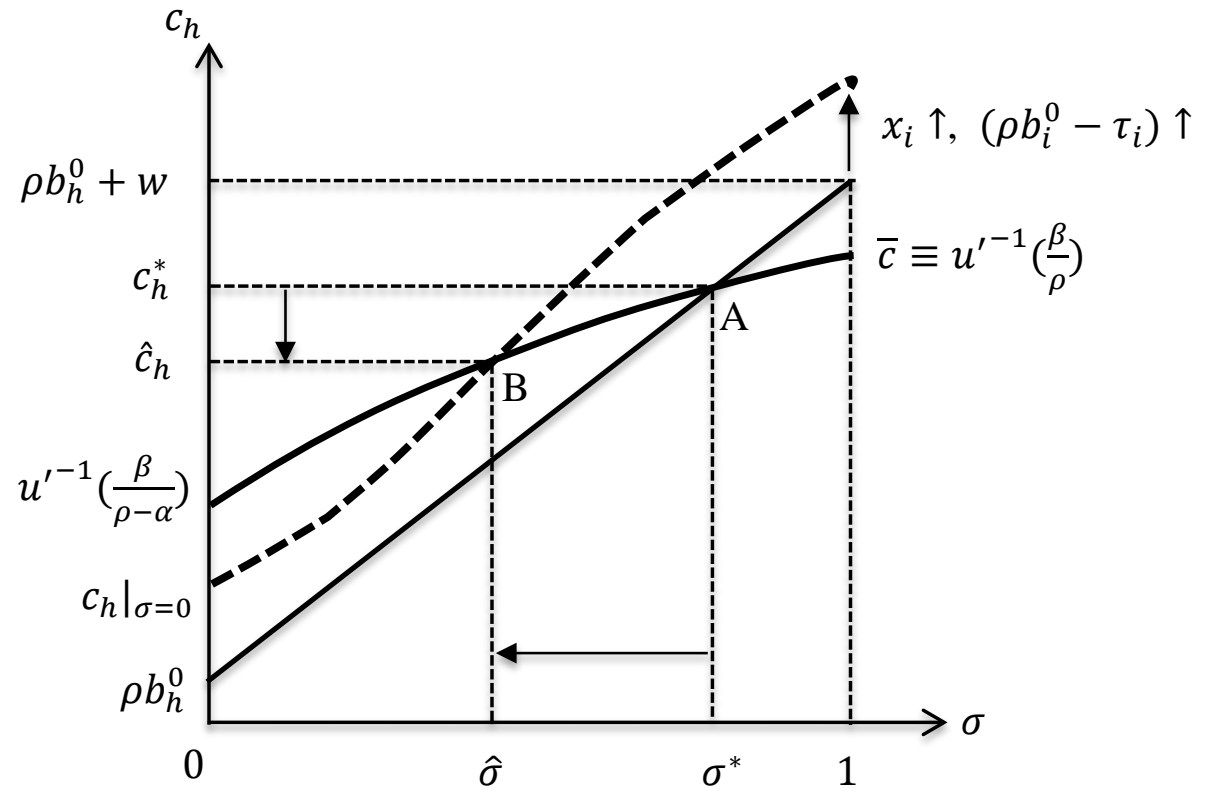

Figure 2

Post- and pre-immigration equilibria with unemployment

(first scenario) 
The host-country’s current account remains balanced despite deflation, validating (25). We can substitute from (36), (37) and (38) into (25) to obtain, after arranging,

$$
c_{h}=w \sigma+\rho b_{h}^{0}+x_{i}[\rho+\alpha(\sigma-1)] m_{i}\left(\sigma ; \rho b_{i}^{0}-\tau_{i}\right) .
$$

This equation and the optimality condition from (35)

$$
\rho+\alpha(\sigma-1)=\frac{\beta}{u^{\prime}\left(c_{h}\right)},
$$

can be solved simultaneously for the native's consumption $\hat{c}_{h}$ and the unemployment rate $\hat{\sigma}$. Substituting this $\hat{\sigma}$ into (37) and (38) gives us the consumption $\hat{c}_{i}$ and real balances $\widehat{m}_{i}$ for the immigrant. In figure 2, the broken curve through point B represents (39) while the solid curve depicts equation (40). Note that (40) is identical to (18) in section 3.

Having solved the model, we can appeal to figure 2 to derive the conditions guaranteeing the existence of an equilibrium with unemployment. To ensure that $\hat{\sigma}<1$, the broken curve needs to take a greater value at $\sigma=1$ than the solid curve does in figure 2 . This requirement is fulfilled if

$$
\left.c_{h}\right|_{\sigma=1} \equiv w+\rho\left(b_{h}^{0}+x_{i} m_{i}\left(1 ; \rho b_{i}^{0}-\tau_{i}\right)\right)>\bar{c},
$$

where $\left.c_{h}\right|_{\sigma=1}$ is the value of $c_{h}$ in (39) for $\sigma=1$. Since $x_{i} m_{i}>0$, this condition necessarily holds if

$$
c_{h}^{F} \equiv \rho b_{h}^{0}+w>\bar{c} .
$$

i.e., the host country has unemployment before immigration; cf. corollary 1 . Further, to have $\hat{\sigma}$ in $(0,1)$ requires that

$$
\left.c_{h}\right|_{\sigma=0} \equiv \rho b_{h}^{0}+(\rho-\alpha) x_{i} m_{i}\left(0 ; \rho b_{i}^{0}-\tau_{i}\right)<u^{\prime-1}\left(\frac{\beta}{\rho-\alpha}\right),
$$

or the broken curve takes a smaller value than the solid curve at $\sigma=0 .{ }^{14}$

\footnotetext{
${ }^{14}$ Given condition (20), this condition holds if $x_{i}$ is not too large.
} 
It is easy to check from (37) and (39) that an increase in the immigrant's net worth $\rho b_{i}^{0}-$ $\tau_{i}$ shifts the dotted curve up. Since (40) is unaffected, the solid curve through A remains intact. Hence, we conclude that both $\hat{\sigma}$ and $\hat{c}_{h}$ decrease as the immigrant's net worth increases.

Manipulation of (39) and (40) yields

$$
\begin{gathered}
d c_{h}=\left(w+\alpha x_{i} m_{i}\right) d \sigma+\frac{\beta x_{i}}{u^{\prime}} d m_{i}, \\
\alpha d \sigma=-\frac{\beta u^{\prime \prime}}{\left(u^{\prime}\right)^{2}} d c_{h} .
\end{gathered}
$$

Combining these equations and using the definition of $\Omega(>0)$ given in (21), we find that

$$
\left(\frac{\beta x_{i}}{u^{\prime}}\right) \frac{d m_{i}}{d\left(\rho b_{i}^{0}-\tau_{i}\right)}=-(\Omega+w) \frac{d \sigma}{d\left(\rho b_{i}^{0}-\tau_{i}\right)}
$$

This equation shows that the immigrant increases his real balances $m_{i}$ as his net worth increases, since $\frac{d \widehat{\sigma}}{d\left(\rho b_{i}^{0}-\tau_{i}\right)}<0$ as is readily confirmed in figure 2 . Therefore, there is the cutoff net worth $\rho b_{i}^{0}-\tau_{i}$ at which $m_{i}=\bar{m}$. If the immigrant' net worth grows still, he must hold $m_{i}>\bar{m}$. In such a case, (37) no longer applies and we have to consider the second scenario.

The second scenario occurs only if the native is rich enough to hold real balances greater than $\bar{m}$. Then we have $v^{\prime}\left(m_{i}\right)=\beta$. Substituting this marginal utility into (35) yields

$$
\rho+\alpha(\sigma-1)=\frac{\beta}{u^{\prime}(c)} \text { with } c_{h}=c_{i}=c .
$$

Thus in the second senario the immigrant is rich enough to consume exactly the same amount of the good as the native. Setting $c_{h}=c_{i}=c$ in (25) enables us to rewrite the host-country current account constraint, which must be in balance, as

$$
\dot{b}=\rho b_{h}^{0}+x_{i}\left(\rho b_{i}^{0}-\tau_{i}\right)+\left(1+x_{i}\right)(w \sigma-c)=0,
$$

which can be arranged to yield

$$
c=c_{h}=w \sigma+\frac{\rho b_{h}^{0}+x_{i}\left(\rho b_{i}^{0}-\tau_{i}\right)}{1+x_{i}} .
$$

(41) and (43) jointly determine the equilibrium values of $c$ and $\sigma$, which we denote by $\hat{c}(=$ $\left.\hat{c}_{h}=\hat{c}_{i}\right)$ and $\hat{\sigma}$. 
In figure 3, the broken line through point $\mathrm{C}$ represents equation (43) whereas the solid curve traces equation (41). The intersection at $C$ indicates the equilibrium values, $\hat{c}_{h}\left(=\hat{c}_{i}\right)$ and $\hat{\sigma}$. To have $0<\hat{\sigma}<1$, we require that

$$
\begin{gathered}
c_{\mid \sigma=1}=w+\frac{\rho b_{h}^{0}+x_{i}\left(\rho b_{i}^{0}-\tau_{i}\right)}{1+x_{i}}>u^{\prime-1}\left(\frac{\beta}{\rho}\right)=\bar{c}, \\
c_{\mid \sigma=0}=\frac{\rho b_{h}^{0}+x_{i}\left(\rho b_{i}^{0}-\tau_{i}\right)}{1+x_{i}}<u^{\prime-1}\left(\frac{\beta}{\rho-\alpha}\right) .
\end{gathered}
$$

These conditions ensure that the broken line lies above the curve near $\sigma=1$ and below it near $\sigma=0$ as in figure 3, guaranteeing the existence of an equilibrium with unemployment.

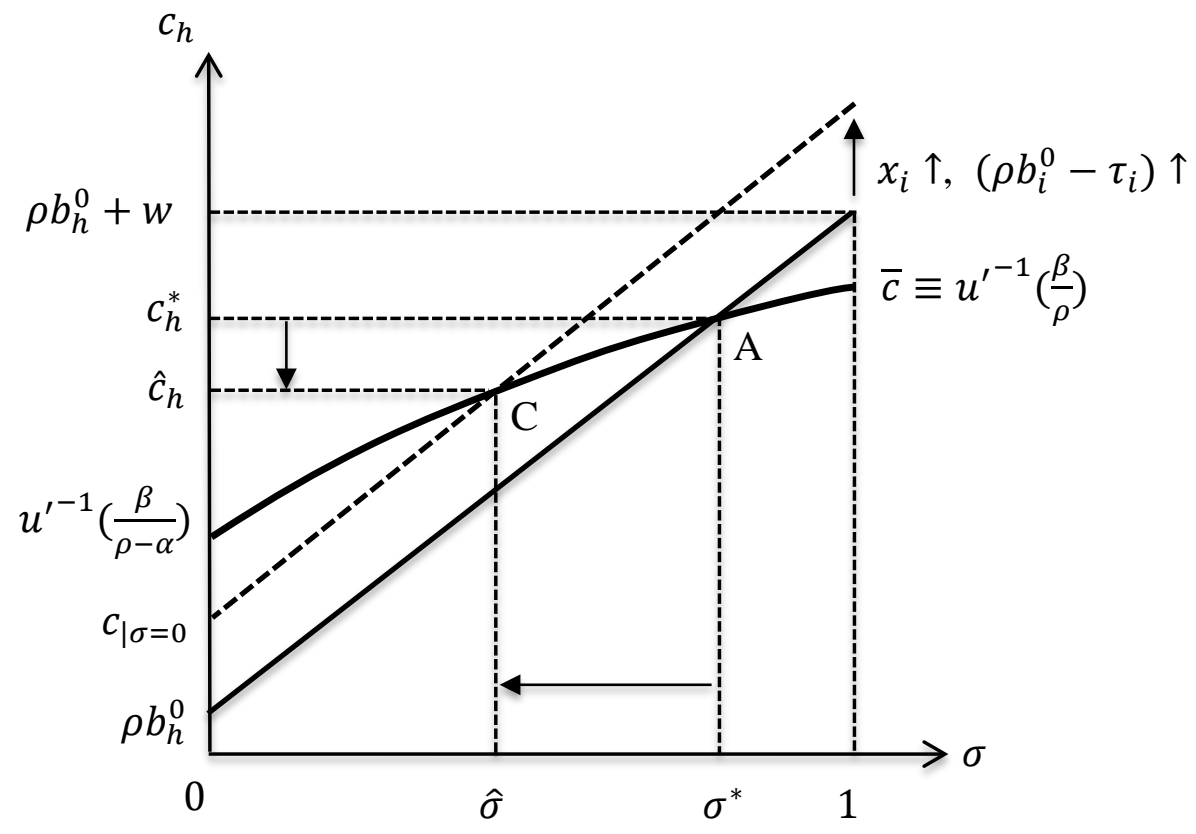

Figure 3:

Pre- and post-immigration equilibria exhibiting unemployment (scenario 2)

To understand conditions (44), notice that $c_{h}=c_{i}$ from (41) implies that the immigrant consumes $c_{i}=c_{h}=w \sigma+\rho b_{h}^{0}$, where the last equality is due to (14). On the other hand, in the present scenario the immigrant sells bonds to acquire real balances greater than $\bar{m}$ so his 
income is at most equal to $\rho\left(b_{i}^{0}-\bar{m}\right)-\tau_{i}+w \sigma$. Since individuals consume their entire incomes, the above observations give us

$$
w \sigma+\rho b_{h}^{0} \leq \rho\left(b_{i}^{0}-\bar{m}\right)-\tau_{i}+w \sigma,
$$

which simplifies to

$$
\rho b_{h}^{0}<\rho b_{i}^{0}-\tau_{i}
$$

(45) implies that $c_{\mid \sigma=1}$ in (44) increases with $x_{i}$. Further, if the host country has unemployment before immigration, (19) and (20) hold. Therefore, the first condition in (44) necessarily holds while the second holds for a sufficiently small $x_{i}$.

Although immigration in the presence of unemployment gives rise to the two distinct scenarios just discussed, depending on the immigrant's net worth, the qualitative effect of immigration is the same. We demonstrate this result with the help of figures 2 and 3 . Recall that in both figures, point A marks the pre-immigration values $c_{h}^{*}$ and $\sigma^{*}$, taken from figure 1 . As $x_{i} \rightarrow 0$, equation (39) approaches equation (14), i.e., in figure 2 the broken curve converges to the straight line, with point $\mathrm{B}$ approaching point $\mathrm{A} .{ }^{15}$ Thus, when the host country has unemployment initially, immigration decreases both the employment rate and natives' consumption level. We observe similar results in figure 3; as $x_{i}$ increases from zero, the broken line given by (43) shifts upward from the solid line because (45) holds. Accordingly, the equilibrium moves from A toward C, decreasing both the employment rate and the native's consumption. The proposition restates the above result.

Proposition 5: If the host country suffers from unemployment initially, immigration always decreases the rate of employment and the native's consumption.

\footnotetext{
15 This guarantees the existence of a unique equilibrium for sufficiently small $x_{i}$.
} 
Earlier, we showed that in figure 2 an increase in the immigrant's net worth shifts the broken curve upward, decreasing the employment rate and the native's consumption level. An inspection of (43) gives us the same result in figure 3 as an increase in $\rho b_{i}^{0}-\tau_{i}$ shifts the broken line upward. We record these observations in the next proposition, which contrast sharply with proposition 4.

Proposition 6: Suppose that the host country has unemployment after immigration.

(a) The richer the immigrants are (in terms of international bond holdings), the lower are the employment rate and the consumption level by natives.

(b) The more remittances the immigrants make, the higher are the employment rate and the consumption level by natives.

\section{Concluding remarks}

In this paper we develop a dynamic model of a small open country, where agents maximize life-time welfare over consumption of the aggregate good and real balances they hold. The model has two salient features: lower boundedness of marginal utility of real balances and sluggish nominal wage adjustment. We find the following. (1) In the absence of immigration, the host country enjoys full employment if it holds a quantity of international interest-earning assets below some threshold level. Otherwise, it has unemployment. (2) If the host country has full employment, an influx of immigrants boosts the native's consumption level, provided that immigrants are neither too rich nor too numerous. An influx of too rich or too many immigrants can give rise to unemployment, however. (3) If the host country suffers from unemployment, an influx of immigration always worsens the unemployment rate while reducing the native's consumption. (4) Remittances immigrants make to their relatives overseas reduce consumption by natives when the host country has full employment. By 
contrast, when the host country has unemployment, remittances increase natives’ consumption as well as their employment.

Several extensions manifest themselves. First, although we assumed native and immigrant workers to be homogeneous, some studies have explored the implications of skill differences between them. ${ }^{16}$ If there is a single aggregate good, one straightforward way to introduce the inferiority of immigrant labor into our model is as follows. Assume that the immigrant possesses only a fraction of (effective) labor compared with the native. Then the immigrant earns a lower wage than the native. In this setting, we expect our qualitative results to remain unaffected. Second, our model can be applied to study the effect of emigration on the source country. More challenging is an extension to the case of two large countries and labor movement between them, since this necessarily introduces interdependence both on the real and the monetary side of the two economies. ${ }^{17}$ We hope to address these issues in our future research.

\footnotetext{
${ }^{16}$ See, e.g., Liu (2010), Chassambouilli and Palivos (2014) and Battisti et al. (2018), who have used two-sector models.

${ }^{17}$ Ono $(2014,2018)$ have studied policy interdependence between large countries without consideration of immigration issues.
} 


\section{Appendix: Stability}

The stability around the full-employment steady state is standard so we focus on the case with unemployment. As mentioned in deriving (11), $c_{j}$ stays constant over time in all cases. Having this property in mind, we first examine the benchmark model with unemployment. From (18) we have

$$
\rho+\alpha(\sigma-1)=\frac{\beta}{u^{\prime}\left(c_{h}\right)} \Rightarrow c_{h}=c_{h}(\sigma)
$$

Substituting this $c_{h}$ to (13) gives us

$$
\begin{gathered}
\dot{b}_{h}=\rho b_{h}+w \sigma-c_{h}(\sigma), \\
\frac{\partial \dot{b}_{h}}{\partial \sigma}=w+\left(\frac{\alpha}{\beta}\right) \frac{\left(u^{\prime}\right)^{2}}{u^{\prime \prime}} \equiv \Omega>0,
\end{gathered}
$$

where $\Omega$ is given in (21). These two equations indicate that the dynamics of $b_{h}$ is unstable, implying that $\sigma$ and $c_{h}(\sigma)$ immediately jump to the levels that makes $\dot{b}_{h}=0$ and stays there, keeping $b_{h}$ at the initial level $b_{h}^{0}$.

Turning next to the post-immigration steady state with unemployment, consider the second scenario from the text, in which both natives and immigrants hold real balances above $\bar{m}$; i.e., $v^{\prime}\left(m_{j}\right)=\beta$ for $j=h, i$. In this case, the post-immigration dynamics is given by (42) and the analysis goes through as above, mutatis mutandis, with $b_{h}$ being replaced by $b_{h}+$ $x_{i}\left(b_{i}-\tau_{i} / \rho\right)$. Consider next the first scenario, in which $m_{h}>\bar{m}$ while $m_{i}<\bar{m}$. In this case, $c_{h}(\sigma)$ is given by (A1) while (35) yields

$$
\frac{v^{\prime}\left(m_{i}\right)}{u^{\prime}\left(c_{i}\right)}-\alpha(\sigma-1)=\rho \Rightarrow m_{i}=m_{i}\left(c_{i}, \sigma\right) .
$$

Applying these $c_{h}(\sigma)$ and $m_{i}\left(c_{i}, \sigma\right)$ to the dynamics of the immigrant's asset holdings in (24) and the current account in (25), we obtain

$$
\begin{gathered}
\dot{a}_{i}=\rho b_{i}^{0}-\tau_{i}+w \sigma-[\rho+\alpha(\sigma-1)] m_{i}\left(c_{i}, \sigma\right)-c_{i}, \\
\dot{b}=\rho\left(b_{h}^{0}+x_{i} b_{i}^{0}\right)+w \sigma\left(1+x_{i}\right)-\left(c_{h}(\sigma)+x_{i} c_{i}\right)-x_{i} \tau_{i},
\end{gathered}
$$


where $\sigma$ and $c_{i}$ stay constant over time. If they jump so that $\dot{a}_{i}$ and/or $\dot{b}$ are non-zero, either the feasibility or non-Ponzi game condition is violated. Thus, they initially jump to the levels that makes $\dot{a}_{i}$ and $\dot{b}$ zero and stay invariant thereafter, i.e., (35) and (36) hold. 


\section{References}

Battisti, M., G. Felbermayr, G. Peri and P. Poutvaara, 2018, Immigration, search and redistribution: a quantitative assessment of native welfare, Journal of the European Economic Association 16, 1137-1188.

Bond, E. W., and T. J. Chen, 1987, The welfare effects of illegal immigration, Journal of International Economics 23, 315-328.

Berry, R. A., and R. Soligo, 1969, Some welfare aspects of international migration, Journal of Political Economy 77, 778-794.

Carter, T. J., 1999, Illegal immigration in an efficiency wage model, Journal of International Economics 49, 385-401.

Chassamboulli, A., and T. Palivos, 2014, A search-theoretic approach to the effects of immigration on labor market outcomes, International Economic Review 55, 111-129.

Dixit, A., and V. Norman, 1980, Theory of International Trade, London: Cambridge University Press.

Djajić, S., 1997, Illegal immigration and resource allocation, International Economic Review 38, 97-117.

Ethier, W. J., 1985, International trade and labor migration, American Economic Review 75, 691-707.

Ethier, W. J., 1986, Illegal immigration: the host-country problem, American Economic Review 76, 56-71.

Giordani, P. E., and M. Ruta, 2013, Coordination failures in immigration policy, Journal of International Economics 89, 55-67.

Illing, G., Y. Ono, and M. Schlegl, 2018, Credit booms, debt overhang and secular stagnation, European Economic Review 108, 78-104.

Liu, X., 2010, On the macroeconomic and welfare effects of illegal immigration, Journal of 
Economic Dynamics and Control 34, 2547-2567.

Mangin, S., and Y. Zenou, 2016, Illegal migration and policy enforcement, Economics Letters 148, 83-86.

Markusen, J. R., 1983, Factor movements and commodity trade as complements, Journal of International Economics 14, 341-356.

Michau, J.B., 2018, Secular stagnation: theory and remedies, Journal of Economic Theory 176, 552-618.

Miyagiwa, K., and Y. Sato, 2019, Illegal immigration, unemployment, and multiple destinations, Journal of Regional Science 59, 118-144.

Ono, Y., 1994, Money, Interest, and Stagnation - Dynamic Theory and Keynes’s Economics, Oxford: Clarendon Press.

Ono, Y., 2001, A reinterpretation of chapter 17 of Keynes’s General Theory: effective demand shortage under dynamic optimization, International Economic Review 42, 207-236.

Ono, Y., 2010, Japan's long-run stagnation and economic policies, in B. Bateman, T. Hirai, M.C. Marcuzzo, eds., The Return to Keynes, Cambridge. Mass.: Harvard University Press, 32-50.

Ono, Y., 2014, International economic interdependence and exchange-rate adjustment under persistent stagnation, Japanese Economic Review 65, 70-92.

Ono, Y., 2018, Macroeconomic interdependence between a stagnant and a fully employed country, Japanese Economic Review 69, 450-477.

Ono, Y., and J. Ishida, 2014, On persistent demand shortages: a behavioral approach, Japanese Economic Review 65, 42-69.

Ortega, J., 2000, Pareto-improving immigration in an economy with equilibrium unemployment, Economic Journal 110, 92-112.

Pissarides, C. A., 2000, Equilibrium Unemployment Theory, Cambridge, Mass.: MIT Press. 
Schmitt-Grohé, S., and M. Uribe, 2016, Downward nominal wage rigidity, currency pegs, and involuntary unemployment, Journal of Political Economy 124, 1466-1514.

Schmitt-Grohé, S., and M. Uribe, 2017, Liquidity traps and jobless recoveries, American Economic Journal: Macroeconomics 9, 165-204.

Wooldland, A. D., and C. Yoshida, 2006, Risk preferences, immigration policy and illegal immigration, Journal of Development Economics 81, 500-513. 